\title{
LA CARGA DINÁMICA PROBATORIA Y SU REPERCUSIÓN EN EL PROCESO PENAL DESDE LAS REGLAS DE MALLORCA Y LA TEORÍA DEL GARANTISMO PENAL*
}

\author{
Sebastián Betancourt Restrepo**
}

Fecha de recepción: 13 de agosto de 2010 • Fecha de aceptación: 23 de septiembre de 2010

\section{Resumen}

El presente artículo pretende hacer algunos cuestionamientos en torno a la implementación de la teoría de la carga dinámica de la prueba en la actuación penal, a partir de los elementos brindados por las Reglas de Mallorca y la teoría del garantismo penal, defendida por el profesor Luigi Ferrajoli en Italia, y en Argentina por el profesor Adolfo Alvarado Velloso, desde la perspectiva de una sistemática procesal penal, reconocedora de garantías universales como el debido proceso.

Palabras clave: carga de la prueba, proceso, acusación, debido proceso, defensa, garantismo, in dubio pro reo, presunción de inocencia.

* Ponencia ganadora del primer premio en el Concurso Internacional para Estudiantes de Derecho, celebrado en el marco del XI Congreso Nacional de Derecho Procesal Garantista, realizado los días 21 y 22 de octubre de 2010 en la ciudad de Azul, provincia de Buenos Aires, Argentina. El presente trabajo es fruto de la reflexión del semillero de investigación de Derecho Procesal de la Facultad de Derecho de la Universidad Autónoma Latinoamericana-UNAULA.

** Estudiante de quinto año de Derecho de la Universidad Autónoma Latinoamericana -UNAUlA, Medellín, Colombia. Asistente de Relaciones Internacionales de la mencionada institución. Becario de la Universidad Nacional de Rosario, Argentina. Correo electrónico: sebas_freeman@hotmail.com. Calle 39A, 59 CC-19. Bello, Antioquia. 


\section{Abstract}

This essay wants to make some questionings around the application of the dynamic evidence charge in criminal process, starting from the point of view given by the Mallorca rules and the criminal guarantee theory, defended by Luigi Ferrajoli in Italy, and Adolfo Alvarado Velloso, in Argentina, from a criminal systematic judgment recognizer of universal rights, as the due process of law.

Keywords: Evidence charge, process, acusation, due process, defense, criminal guarantee theory, in dubio pro reo, innocence presumption. 


\section{INTRODUCCIÓN}

El instituto de la carga dinámica de la prueba significa en esencia que el onus probandi recae en aquel sujeto procesal que esté en mejores condiciones técnicas, profesionales o fácticas de aportar la prueba pertinente para demostrar su afirmación, sin consideración de su posición de demandante o demandado (Peyrano en Peyrano y Lépori, 2004). Esta doctrina tuvo gran acogida en el Derecho Privado en muchos temas como la responsabilidad médica o las pretensiones de actos simulados, y dejó atrás aquella era de "pruebas diabólicas", bien fuera para el pretendiente o para el resistente, pero su fuerza expansiva no se limitó solo al Derecho Civil, sino que también permeó al Derecho Penal, dejando en manos de la defensa casi todo el ejercicio probatorio del juicio.

El presente trabajo pretende hacer una aproximación crítica a la mencionada figura en el ámbito de la actuación penal, examinando si ella se ajusta o no a las prescripciones del "Proyecto de reglas mínimas de las Naciones Unidas para la administración de la Justicia Penal" o Reglas de Mallorca, a partir de la interpretación que la sala de casación penal de la Corte Suprema de Justicia de Colombia ha hecho sobre el tópico, en consonancia con la doctrina del garantismo penal expuesta por el profesor Luigi Ferrajoli.

\section{LA CARGA PROBATORIA DINÁMICA EN EL PROCESO PENAL}

Antes de entrar al análisis concreto de los pronunciamientos de la Corte Suprema de Justicia, conviene detenerse un poco en los caracteres principales de la teoría de la carga dinámica de la prueba, lo que permitirá dilucidar cuán acertado es el dictamen del Alto Tribunal.

Esta institución, como se ha dicho, traduce que quien esté en mejores condiciones de aportar una prueba debe hacerlo, así en principio ello no lo corresponda. Es en tal situación donde se produce un desplazamiento del onus probandi, atendiendo a

[...] una posición privilegiada o destacada con relación al material probatorio o a su contraparte. Es decir, que en virtud del rol que desempeñó en el hecho generador de la controversia, por estar en 
posesión de la cosa o instrumento probatorio o por ser el único que 'dispone' de la prueba... (Barberio, en Peyrano y Lépori, 2004:101)

Así mismo, el movimiento indicado en el deber de probar es fruto del principio de colaboración y solidaridad entre las partes (Barberio, en Peyrano y Lépori, 2004), dado que la actividad de los sujetos procesales va encaminada a la corroboración de las afirmaciones hechas por ambas mediante el ejercicio de la función jurisdiccional. Lo anterior se justifica porque muchas veces se construye el debate litigioso sobre "...las bases de una presunción con los escasos indicios que existen, que siempre existen”. (Nieva, en Acero, Bermúdez, Buitrago et al. 2009: 1030)

Una segunda característica consiste en que su aplicación es excepcional, de tal manera que solo tendrá cabida el traspaso de probar de una parte a la otra, cuando las reglas generales de la carga probatoria sean perjudiciales al aplicárseles a eventos igualmente excepcionales, pues tales normas solo operan para supuestos normales y corrientes, al decir de Peyrano (2004).

Igualmente, la doctrina de la carga probatoria dinámica y los efectos que ella pueda generar dentro del proceso, dependen más de la valoración que haga el juez frente al comportamiento de las partes en el debate probatorio, que del aporte de la prueba realizada por éstas, pues en uno u otro caso, el juzgador debe decidir ateniéndose a lo introducido por el actor y el resistente: "En rigor, más que atribuirle la carga probatoria, se le endilgan las consecuencias de la omisión probatoria. A nadie escapa que las reglas de distribución de la carga de la prueba solo tienen importancia cuando, precisamente, no hay prueba." (Barberio, en Peyrano y Lépori, 2004:102)

Como última nota esencial de la institución comentada, la aplicación de la misma depende de cada caso en concreto. No es posible elaborar un derrotero rígido que permita saber cuándo debe hacerse un traslado o aligeramiento en la carga de la prueba (Airasca, en Peyrano y Lépori, 2004), ya que ello traería las mismas consecuencias nocivas que la aplicación de las reglas generales sobre las cargas probatorias acarrearía.

\section{LA CARGA DINÁMICA DE LA PRUEBA Y LA TEORÍA DEL GARANTISMO PENAL}

El profesor Ferrajoli en su obra Derecho y razón describe un sistema punible y de enjuiciamiento criminal, encaminado a brindar un máximo 
conjunto de garantías, tanto desde el momento en que el legislador en su libre potestad de configuración legislativa “...crea supuestos típicos dotados de significado unívoco y preciso..." (Ferrajoli, 1997: 95), hasta que en el desarrollo de la acusación y el juicio penales el fallador constata los presupuestos empíricos denotados legalmente para endilgar responsabilidad penal, y en consecuencia, aplicar una sanción punitiva: “...el juez comprueba o prueba como verdadero (que se ha cometido un delito) solo (si el hecho comprobado o probado corresponde a) lo que está taxativamente denotado por la ley como delito." (Ferrajoli, 1997: 96)

El sistema garantista está construido bajo los siguientes axiomas:

A1 Nulla poena sine crimine.

A2 Nullum crimen sine lege.

A3 Nulla lex (poenalis) sine necessitate.

A4 Nulla necessitas sine iniuria.

A5 Nullainiuria sine actione.

A6 Nulla actio sine culpa.

A7 Nulla culpasine iudicio.

A8 Nullum iudicium sine accusatione.

A9 Nulla accusatio sine probatione.

A10 Nulla probatio sine defensione.

Cada axioma anterior corresponde respectivamente a los siguientes principios continentes de garantías penales - o sustanciales si se quierey procesales, según el profesor Ferrajoli (1997:93):

1. Principio de retributividad o de la sucesividad de la pena respecto del delito

2. Principio de legalidad

3. Principio de necesidad o de economía del Derecho Penal

4. Principio de lesividad o de la ofensividad del acto

5. Principio de materialidad o de la exterioridad de la acción

6. Principio de culpabilidad o de la responsabilidad personal

7. Principio de jurisdiccionalidad

8. Principio acusatorio o de la separación entre juez y acusación 
9. Principio de la carga de la prueba o de verificación

10. Principio del contradictorio, o de la defensa, o de refutación

Los anteriores principios son consecuencia directa y necesaria de su antecedente, lo que significa que la interrupción de la cadena principialística antes descrita, en cualquiera de sus eslabones, torna nugatorio el sistema procesal penal garantista ideado por Ferrajoli, derivando así en alguno de los sistemas autoritarios señalados por el maestro italiano, lo que obviamente degenera en desconocimiento de garantías fundamentales atinentes al debido proceso y a la bilateralidad de la audiencia. Como se aprecia, el instituto procesal de la carga de la prueba se halla en un alto nivel jerárquico dentro de la actuación penal, al punto que ella, al ser efecto inmediato del principio acusatorio, es decir, la necesidad de una previa acusación para dar inicio al juicio, se torna en la figura central del juzgamiento criminal, merced a que de la forma en que se asuma la labor probatoria por parte del Ministerio Público, el juicio habrá de culminar en una condena o en una absolución.

Como la nota esencial de la carga dinámica de la prueba es el desplazamiento del deber de probar hacia quien aparentemente está en mejores condiciones de hacerlo - que en materia penal tal movimiento iría del ente acusador hacia la defensa-, ello entonces se traduce en que el debate probatorio en el juicio queda en manos únicamente de ésta. Por tanto, la Fiscalía se deshace de la carga sustancial de solicitar la práctica de pruebas y la recolección de elementos materiales probatorios en busca de dar sustento a la condena pedida en su acusación, ya que, como se verá más adelante, en ciertas hipótesis delictivas el acusado está en mejores condiciones de probar su inocencia al intentar enervar afirmaciones indefinidas hechas por el Ministerio Público.

Por ende, la asunción de la defensa de un deber propio e inexcusable del ente acusador, merced a la implementación de la figura de la carga dinámica de la prueba en la actuación penal, equivale a la supresión, dentro del sistema garantista ferrajoliano, de los axiomas A9 - "Nulla acusatio sine probatione", correspondiente al principio de carga de la prueba o de verificación- y A10 — "Nulla probatio sine defensione"-, que atañe al principio del contradictorio, o de la defensa, o de refutación. La ausencia de estos caros elementos en el sistema procesal penal garantista entorpece, e 
inclusive puede llegar a hacer nulo el genuino rol que como defensor debe ejecutar este togado, pues se le exige el absurdo de demostrar la inocencia de su prohijado, atacando afirmaciones o negaciones indeterminadas no susceptibles de ser probadas ni controvertidas, cuando ello es una garantía constitucional y procesal no susceptible de excepción y que hace parte del jus cogens en materia de derechos humanos consagrados en tratados internacionales y en las Reglas de Mallorca, ya que lo que debe aplicarse sin dubitación es la regla del non liqueat, y abstenerse de dictar sentencia, como lo afirma el profesor Alvarado Velloso (2006).

Así, se destaca que la falta de estos axiomas denle el sistema garantista, impide el adecuado desarrollo del juicio y el contradictorio, pues estos principios no pueden desenvolverse adecuadamente al interior del juzgamiento, ante la falta recíproca de ambos. Y en virtud de la interdependencia de cada uno de estos axiomas del sistema, el juicio es apenas un acto simbólico y vacío, ante la ausencia de afirmaciones concretas con vocación condenatoria del Ministerio Público, pues el desplazamiento de su obligación de probar hacia la defensa, es una muestra de la imposibilidad de satisfacer el estándar probatorio de la acusación, a saber, probabilidad de verdad de que la conducta existió y que el acusado es su autor o partícipe, siendo lo acertado desde el punto de vista de las garantías constitucionales y procesales afirmar con el profesor Alvarado Velloso que “...quien debió confirmar su afirmación y no lo hizo, pierde el pleito aunque su contraparte no haya hecho nada al respecto" (2006: 46).

Este inquietante instituto de la carga dinámica probatoria, torna el sistema garantista de Ferrajoli en uno de los sistemas autoritarios de juicio penal señalados por el mismo autor florentino, ante la injustificada y arbitraria extracción de dos de sus axiomas centrales, como ya se señaló. Tal degenerado modelo es un sistema carente de defensa y prueba, o de mera legalidad (Ferrajoli, 1997: 98), puesto que “....acusación y defensa son solo argumentables pero no también verificables y refutables, estas mismas garantías están presentes solo en sentido lato" (Ferrajoli, 1997: 98), habida cuenta de que tales prebendas están solo consagradas formalmente, pero el sistema no ofrece reales alternativas para hacerlas efectivas durante el juicio.

Luigi Ferrajoli es bastante incisivo al insistir en la necesidad de recuperar el carácter recognoscitivo del juicio penal, y se opone en consecuencia a una concepción constitutiva de éste: 
Al propio tiempo, para que el juicio no sea apodíctico, sino que se base en el control empírico, es preciso también que las hipótesis acusatorias [...] sean concretamente sometidas a verificación y expuestas a refutación, de forma que resulten convalidadas solo si resultan apoyadas por pruebas y contrapruebas según la máxima nullumiudicium sine probatione. (Ferrajoli, 1997: 37).

Y más adelante, agrega:

De ahí se deriva un modelo teórico y normativo del proceso penal como proceso de cognición o de comprobación, donde la determinación del hecho configurado por la ley como delito tiene el carácter de un procedimiento probatorio de tipo inductivo, que excluye las valoraciones en lo más posible y admite sólo, o predominantemente, aserciones o negaciones — de hecho o de derecho-, de las que sean predicables la verdad o la falsedad procesal [...]. (Ferrajoli, 1997: 37).

Por ello, deben seguirse estrictamente y con interpretación restrictiva las reglas legales sobre la carga de la prueba, con miras a evitar que el activismo judicial opaque de ilegítimo el proceso penal, como lo sostiene el ya citado profesor rosarino (Alvarado, 2006).

Las anteriores citas pretenden indicar la clave de bóveda de todo el sistema penal, tanto en lo relativo a la determinación de las conductas punibles, como a su juzgamiento, en cuanto a que la conjunción amónica de los principios de estricta legalidad ${ }^{1}$ y de estricta jurisdiccionalidad ${ }^{2}$, debe impedir la creación o constitución de conductas delictivas al interior del juicio. Desafortunadamente, a ello apunta la carga dinámica de la prueba, puesto que abre las puertas para fáciles y numerosas condenas, sin sustento alguno en convincentes elementos probatorios, ya que éstas surgen solo de elucubraciones del acusador en su afán de eficientismo penal y, paralelo a ello, procurar ocultar una investigación criminal pobre, atentando contra la

1 "[...] hecho unívocamente descrito y denotado como delito no solo por la ley, sino también por la hipótesis de acusación, de modo que resulte susceptible de prueba [...]”. (Ferrajoli, 1997: 37).

2 “...verificabilidad o refutabilidad de las hipótesis acusatorias en virtud de su carácter asertivo y su prueba empírica en virtud de procedimientos que permitan tanto la verificación como la refutación". (Ferrajoli, 1997: 37). 
jurisdiccionalidad estricta. Se trata entonces de una "... actitud tramposa, sino que, en el proceso, viola la garantía de la defensa en juicio. ¡Por mucho empeño justiciero que ostente el juez actuante!". (Alvarado, 2006: 50)

Por último, se resalta, aunque ya se ha insinuado líneas arriba, que la carga dinámica de la prueba viola la carga acusatoria de la prueba, en virtud de que dentro del sistema garantista de Ferrajoli, está proscrita toda colaboración implícita o tenue que el acusado le haga a su acusador, que es lo que en el fondo hace la carga dinámica de la prueba al tratar de salvar las deficiencias investigativas del Ministerio Público. El principio de contradicción se desdibuja “.... a causa de la confusión de papeles entre las partes y por el carácter de monólogo que se imprime a toda la actividad procesal..." (Ferrajoli, 1997: 609).

\section{LA POSICIÓN DE LA CORTE SUPREMA DE JUSTICIA DE COLOMBIA FRENTE A LAS CARGAS PROBATORIAS DINÁMICAS}

Vistas las generalidades que rigen a la teoría de la carga dinámica de la prueba, se pasa a estudiar tres fallos de la sala de casación penal de la Corte Suprema de Justicia colombiana que han abordado el tema.

\subsection{Sentencia de casación de nueve de abril de 2008, radicado 23754}

En este fallo, la Corte entra a decidir sobre la demanda de casación interpuesta por la defensa y la Fiscalía, contra la sentencia del Tribunal Superior de Bogotá, que confirmó la condena por lavado de activos y la absolución de enriquecimiento ilícito. Los hechos fueron los siguientes:

El 5 de septiembre de 2002, en el Aeropuerto Internacional El Dorado de la ciudad de Bogotá, fue retenida la señora María Mercedes Gómez Gómez, cuando arribó procedente de la ciudad de Madrid (España), con ciento siete mil doscientos dólares (US \$ 107.200) en efectivo, camuflados en cajas de rollos de película para cámaras fotográficas, dinero que no había sido declarado ante la Dirección de Aduanas Nacionales.

La defensa solicita que se case la condena por lavado de activos, ya que la misma se basó solo en presuposiciones. A su vez, la Fiscalía solicita la imposición de la agravante de lavado de activos por operaciones cambiarias y que se condene por enriquecimiento ilícito de particulares. 
I. La Corte decide no casar la condena por lavado de activos solicitada por la defensa, bajo las siguientes consideraciones:

De cara al lavado de activos, asevera el Alto Tribunal que no es necesario que haya una sentencia condenatoria previa referida a los actos ilegales que dan origen a los activos. Solo basta con que no se demuestre legítimamente por parte del procesado, la tenencia legal de dichos bienes. Se observa aquí una inversión de la carga probatoria del ente acusador hacia al acusado en virtud de la carga dinámica de la prueba, pues le corresponde a éste corroborar un hecho negativo, como lo es su inocencia, ante la imposibilidad de la Fiscalía de acreditar el origen ilícito de los activos blanqueados.

Y ello no es todo: la Corte afirma que "...la actividad ilegal subyacente [al lavado de activos] solo requiere de una inferencia lógica que la fundamente..." (Corte Suprema de Justicia. Sentencia de casación 23754 de nueve de abril de 2008) ${ }^{3}$, es decir, basta tan solo con una declaración judicial que indique que efectivamente el dinero tiene procedencia ilegítima, sin que ello implique un adecuado debate probatorio para demostrar tal circunstancia. Significa lo anterior serias lesiones al derecho a una defensa material, ya que el procesado debe defenderse no solo de la acusación del lavado de activos sino también de otro delito inexistente en el pliego de cargos y que puede ser indeterminado, pues como se dijo arriba, se estructura simplemente con la no demostración del origen legal de los bienes. También se conculca la presunción de inocencia, pues la ilegalidad del dinero blanqueado parte de una simple inferencia que hace el juzgador y que no atiende al desarrollo probatorio dado al interior de la actuación, pues la alteración en el onusprobandi se produce ante la imposibilidad de la Fiscalía de demostrar con certeza la proveniencia ilegítima del dinero. Esto último constituye una seria transgresión al debido proceso probatorio, y al in dubio pro reo, ya que las dudas que se ciernen sobre el origen del dinero se resuelven a favor de la acusación. La sala de casación penal de la Corte así lo ha expresado: 
Se insiste: la imputación por lavado de activos es autónoma e independiente de cualquier otra conducta punible y para fundamentar la imputación y la sentencia basta que se acredite la existencia de la conducta punible subyacente a título de mera inferencia por la libertad probatoria que marca el sistema penal colombiano. (Corte Suprema de Justicia. Sentencia de casación 23174 de 28 de noviembre de 2007$)^{4}$

No obstante la libertad probatoria mencionada en la antecedida cita, ello no da pie a que el ejercicio de la contradicción probatoria tenga como puntos de partida solo presunciones judiciales que nacen de la imposibilidad del ente acusador de satisfacer adecuadamente el estándar probatorio del juicio — conocimiento más allá de toda duda razonable-, y que solo se ven justificados por una postura eficientista de la justicia penal.

II. La Corte accede parcialmente a las peticiones de la Fiscalía, de tal manera que solo impone condena por el enriquecimiento ilícito de particulares con base en las argumentaciones dadas para confirmar la condena por el lavado de activos, y reiterando la necesidad de la defensa de demostrar el hecho negativo de la inocencia de su prohijada, no obstante reconocer que ello no es una obligación de la defen$\mathrm{sa}^{5}$. Mediante dicho razonamiento se encubre la incapacidad del ente acusador de hallar los elementos materiales probatorios destinados a enervar la presunción de inocencia del acusado.

Es solo bajo esa premisa que nuestro Tribunal de Casación invierte la carga de la prueba, no para permitir el ejercicio de la defensa material, sino para allanar el camino de la acusación:

4 Subrayas nuestras.

5 "Bajo esa lógica, no es obligación del procesado desplegar actividades encaminadas a acreditar su inocencia, pues ello conduciría a exigirle la demostración de un hecho negativo, ya que, se reitera, es el ente acusador el que debe demostrarle su culpabilidad. Ello significa, a la luz del principio del in dubio pro reo, que si no se logra desvirtuar la presunción de inocencia hay que absolver al implicado, pues toda duda debe resolverse a su favor." (Corte Suprema de Justicia. Sentencia de casación 23754 de nueve de abril de 2008). 
Pero, dentro de criterios lógicos y racionales, es claro que existen elementos de juicio o medios probatorios que solo se hallan a la mano del procesado o su defensor y, si estos pretenden ser utilizados por ellos a fin de demostrar circunstancias que controviertan las pruebas objetivas que en su contra ha recaudado el ente instructor, mal puede pedirse de éste conocer esos elementos o la forma de allegarse al proceso. (Corte Suprema de Justicia. Sentencia de casación 23754 de nueve de abril de 2008)

Y más adelante, al referirse expresamente al concepto de carga dinámica de la prueba, asevera que

[...] de ninguna manera repugna el concepto clásico de carga de la prueba en materia penal, ni mucho menos afecta derechos fundamentales del acusado. Simplemente pretende entronizar en el Derecho Penal criterios racionales y eminentemente lógicos respecto de las pretensiones de las partes y los medios necesarios para hacerlas valer. (Corte Suprema de Justicia. Sentencia de casación 23754 de nueve de abril de 2008).

Desafortunadamente, y con el respeto que merece nuestra Alta Corte, el razonamiento realizado ut supra abre las puertas para que la Fiscalía alegue su propia ineptitud al desplegar una investigación penal en la que no ha dado con todos los elementos probatorios inculpatorios que sustenten su pretensión punitiva, con la gravosa consecuencia de salir premiada, pues atendiendo a una parcializada e incompleta interpretación de la doctrina de las cargas probatorias dinámicas, el esfuerzo probatorio se traslada casi de forma completa hacia la defensa, partiendo solo de inferencias judiciales.

\subsection{Sentencia de casación de veintisiete de marzo de 2009, radicado 31103}

La Corte procede a decidir la demanda de casación interpuesta por la Fiscalía en contra de la sentencia del Tribunal Superior de Medellín, que absolvió al procesado de los delitos de acceso carnal violento e incesto. Los hechos fueron los siguientes: 
En la vereda La Palma, zona rural del corregimiento San Cristóbal de la ciudad de Medellín, residían los esposos Julio César Palacio y Luz Mery Muñoz, conjuntamente con sus menores hijos Y, J. y E. Dentro de ese entorno, para mediados del año 2006, Julio César Palacio, aprovechando que su esposa no se hallaba en la vivienda, dadas sus ocupaciones laborales, comenzó a realizar vejámenes físicos y sexuales en contra de Y..., que incluyeron golpes, amenazas con arma de fuego y acceso carnal por vía anal. Ello se prolongó hasta el mes de octubre de ese año, cuando la víctima, pese a la incredulidad de su madre, dio noticia de lo ocurrido a una tía suya, quien puso en conocimiento de las autoridades esos hechos.

El ente acusador sustenta su petición de revocar la absolución y en su lugar confirme la condena del a quo, tanto en una violación directa de norma sustancial, como en una inadecuada apreciación probatoria por parte del ad quem. La Corte casa el proveído del Tribunal Superior de Medellín, acudiendo a los siguientes argumentos:

En primer lugar, el Alto Tribunal le asigna el carácter de prueba directa a los testimonios dados por los familiares de la víctima, aduciendo tal característica por la directa percepción que de los hechos tuvieron las declarantes, por haberse enterado de los presuntos vejámenes sexuales por boca de la próxima víctima. Es éste el primer paso con el que inicia la Corte Suprema para construir la inferencia judicial que servirá de sustento a su decisión.

El segundo punto consiste en una sobrevaloración de los testimonios rendidos durante el juicio, al extremo que es a través de ellos que, tanto el juez de conocimiento como la misma Corte, dan por probados los múltiples accesos carnales presuntamente sufridos por el menor, no obstante que asaltaren dudas respecto a la existencia de los mismos, en atención a que las experticias médicas recaídas sobre la víctima nunca dieron señales de la existencia de los mismos. Lo anterior tiene el objeto de evitar que tales atestaciones tengan el carácter de referenciales, pues al tenerlo, las mismas no podrán ser apreciadas en juicio, ya que no encajan en alguno de los supuestos excepcionales y de interpretación restrictiva que consagra el artículo 438 del Código de Procedimiento Penal. En consecuencia, no es posible predicar conocimiento personal de los hechos que son materia de debate, lo cual es pretermitido tanto por el juez de conocimiento como por la misma sala de casación penal de la Corte Suprema de Justicia. 
Lo anterior es suficiente, a nuestro juicio, para confirmar el fallo de segunda instancia. Sin embargo, la Corte remite nuevamente al concepto de la carga dinámica de la prueba, para que la defensa pueda subsanar las deficiencias investigativas de la Fiscalía, bajo el supuesto de que ello es una imposición de la nueva sistemática acusatoria:

Ahora, en el sistema acusatorio que rige la solución del caso examinado, se hace mucho más evidente esa obligación para la defensa de presentar, si busca derrumbar el efecto de la prueba de cargos, prueba que la desnaturalice o controvierta..." (Corte Suprema de Justicia. Sentencia de casación de veintisiete de marzo de 2009, radicado 31103$)$.

El ejercicio de la defensa ya se realizó, al punto que se obtuvo la absolución en la alzada. Empero lo anterior, la Corte da una desproporcionada carga probatoria a la misma con el objeto de que las inferencias judiciales que dan sustento a su decisión sigan en pie. Se reitera que tal línea de pensamiento va en contravía de la defensa material, el debido proceso probatorio, el in dubio pro reo y la presunción de inocencia; prescripciones que no admiten limitación alguna y que hacen parte de la dogmática constitucional que irriga a todo el proceso penal.

\subsection{Sentencia de casación de trece de mayo de 2009, radicado 31147}

En esta última providencia, la Corte pasa a decidir la demanda de casación interpuesta por el apoderado civil de la Dirección de Impuestos y Aduanas Nacionales, ante la sentencia proferida por el Tribunal Superior de Medellín, que confirmó la absolución del delito de omisión de agente retenedor. Los hechos fueron los siguientes:

El Jefe de la División Jurídica Tributaria de la Dirección de Impuestos y Aduanas Nacionales, denunció ante la Fiscalía al señor Orlando Isaza Estrada, porque dentro del término estipulado en la ley declaró pero no consignó los dineros recaudados por concepto del IVA, en su calidad de representante legal de la "Comercializadora Estándar", dedicada a la venta de aceites para máquinas de coser, desde el período $5^{\circ}$ de 1998 hasta el período $2^{\circ}$ de 2000 , por valor de $\$ 8.093 .000$, más los intereses moratorios, deuda que fue soportada con la documentación que anexó a la denuncia, co- 
rrespondiente a las declaraciones bimestrales del impuesto sobre las ventas presentadas por el procesado.

La Dian, a través de su apoderado civil, solicita que se revoque el fallo absolutorio, y en su lugar se profiera uno condenatorio, ya que la absolución fue producto de una inadecuada valoración probatoria.

La Corte Suprema de Justicia casa la decisión impugnada, y en su lugar emite un fallo condenatorio, gracias al uso de la teoría de la carga probatoria dinámica. Al efecto, desconoce una vez más el Alto Tribunal las reglas que rigen el debate probatorio al interior del proceso penal, justificando tal situación en los siguientes términos:

Lo anterior, porque dentro de criterios lógicos y racionales no puede desconocerse que la dinámica de los acontecimientos enfrenta a la judicatura en muchas de las veces a situaciones en las cuales se aduce la existencia de elementos de juicio o medios probatorios que solo se hallan a la mano del procesado o su defensor, que los invocan para demostrar circunstancias que controvierten las pruebas objetivas que en su contra ha recaudado el ente instructor, y que por lo tanto es a ellos a quienes corresponde allegarlos al proceso si quieren obtener los reconocimientos que de los mismos buscan. (Corte Suprema de Justicia. Sentencia de casación de trece de mayo de 2009, radicado 31147).

De tal manera que la Corte acude nuevamente a las cargas dinámicas probatorias para legitimar las deficiencias en la investigación por parte de la Fiscalía, atribuyendo a la defensa toda la carga de la prueba del juicio, el cual determinará la responsabilidad penal mediante inferencias judiciales, que invierten el sentido de la presunción de inocencia, pues se está presuponiendo la culpabilidad:

Por lo tanto, si la defensa quería demostrar, a partir del ofrecimiento de elementos probatorios concretos y verificables, que parte de los dineros declarados como recaudados por concepto de IVA, no entraron realmente a las arcas del procesado, debió aportar los elementos de juicio necesarios para ello, los cuales de todas maneras no podían exculpar totalmente al procesado, como quiera que éste admitió que parte de los mismos sí fueron efectivamente recibidos, pero que tuvo que destinarlos a otros menesteres por las dificultades económicas 
que atravesó su empresa. (Corte Suprema de Justicia. Sentencia de casación de trece de mayo de 2009, radicado 31147).

En este orden de ideas, se observa que la Corte da por probado que el dinero recaudado y no pagado ingresó al patrimonio del procesado, por el hecho de que éste no acreditó el paradero de tales cantidades. Y la Fiscalía tampoco hizo lo propio, pues a las cargas dinámicas probatorias se accede cuando hay deficiencia probatoria. Recae entonces sobre el investigado, el ejercicio probatorio, la presunción de su culpabilidad y el desconocimiento del imperativo constitucional del in dubio pro reo. La Corte, en un paradójico y controvertido aparte, así lo menciona:

Pero, incluso si hubiese negado haber recibido algún dinero del declarado, era de su resorte ofrecer los medios probatorios necesarios para confirmar el aserto, no porque la carga de la prueba de responsabilidad se desplace en su contra, sino porque a la Fiscalía le resultaba imposible, cuando lo argumentado a título de exculpación operó en la audiencia de juzgamiento, demostrar lo contrario o siquiera corroborar la veracidad de lo expresado por el acusado, después de que había presentado en la oportunidad debida prueba idónea de la recaudación del impuesto por parte del procesado. (Corte Suprema de Justicia. Sentencia de casación de trece de mayo de 2009 , radicado 31147$)^{6}$.

Es desafortunada e insostenible tal argumentación, habida cuenta que ella atenta contra garantías no susceptibles de restricción que deben observarse al interior del juicio, según las Reglas de Mallorca. Gracias a una cuestionable presunción judicial, producto de los débiles elementos materiales probatorios arrimados a la actuación, termina condenándose a una persona, ya que las dudas sobre su responsabilidad fueron resueltas en su contra. 


\section{CONCLUSIONES}

De lo apreciado hasta ahora, salta de bulto la inconveniencia de la aplicación de la teoría de la carga dinámica probatoria en sede del proceso penal. Lo anterior está justificado en que las garantías constitucionales de la presunción de inocencia e in dubio pro reo presentes en éste, zanjan cualquier discusión en torno a las deficiencias probatorias que se presenten dentro de la actuación penal:

[...] si en el iterprocesus se evidencia la falta de pruebas, siguiendo a Maier, rige precisamente allí el principio in dubio pro reo como criterio de solución del caso. El mismo determina que la sentencia de condena tenga como presupuesto la expresión de certeza acerca de todas y cada una de las condiciones para reprochar un hecho punible a una persona determinada; a contrario, fija el criterio que permite dar solución cierta [...] a todos los casos de incerteza; ante cualquier otro grado de conocimiento sobre la imputación que no sea la certeza, corresponde absolver. (Acosta, en Peyrano y Lépori, 2004: 526).

También, es más que acertada la opinión del maestro Alvarado Velloso al respecto:

En definitiva: la ley —y solo la ley, nunca la jurisprudencia- es la que regula todo lo referente a la incumbencia confirmatoria a fin de dar total y objetiva seguridad a la actividad que los jueces cumplen la sentencia, evitando así que ellos puedan alterar las reglas del onus probandi a discreción... (Alvarado, 2006: 50).

Su aplicación en el proceso penal lleva a resultados altamente ignominiosos y dañinos de las garantías fundamentales que se consagran en las Reglas de Mallorca, en la Constitución Política y en el bloque de constitucionalidad. A lo anterior se suma que nuestra Corte Suprema de Justicia parte de una errada comprensión de la doctrina ya comentada, pues considera que no aportar determinado elemento material probatorio en sede de juicio oral, inexorablemente lleva a un resultado adverso para el procesado, como se puede observar en las decisiones comentadas. Sí atina nuestro Alto Tribunal en reconocer su carácter específico y excepcional. 
La única posibilidad de aceptar su implementación, siguiendo a Acosta, sería bajo expresa autorización a nivel constitucional, toda vez que la aplicación de esta doctrina conlleva una seria lesión del debido proceso probatorio, a la defensa material, a la presunción de inocencia y una restricción al in dubio pro reo. Ejemplo de ello es la Constitución de Argentina, en la que expresamente reza en su artículo 36, párrafo quinto, lo siguiente: "Atentará asimismo [sic] contra el sistema democrático quien incurriere en grave delito doloso contra el Estado que conlleve enriquecimiento..."

Sin embargo, tal aseveración es arriesgada y apresurada; además desconoce que el Estado está concebido por y para el hombre, y no en sentido contrario. Así mismo, y contrario a lo expresado por el precitado autor, tal limitación a la presunción de inocencia, a la defensa material, al in dubio pro reo y al debido proceso probatorio, no encuadra dentro de la prescripción del artículo $32.2^{7}$ de la Convención Americana sobre derechos humanos, máxime cuando se reconoce su plena vigencia, inclusive en los estados de excepción. El hecho de que pueda tener algún sustento constitucional no significa que guarde consonancia con el espíritu garantista de los derechos fundamentales procesales, antes bien, su inconstitucionalidad e ilegalidad entra en contravía con lo normado en tratados internacionales de derechos humanos.

La carga dinámica de la prueba es un abuso a los espacios jurisdiccionales discrecionales de denotación -interpretación-, de connotación - comprensión equitativa - y de comprobación probatoria — verificación fáctica-, máxime cuando no existe en el Código de Procedimiento Penal colombiano, alguna norma que la insinúe o justifique. Hasta ahora, es una desafortunada y desacertada interpretación jurisprudencial que urge un cambio de precedente de manera pronta.

Esta inserción jurisprudencial de este instituto, solo puede ser comprendida como un sutil intento de revivir un sistema inquisitorio y decisionista de juzgamiento, ya que como la ley 906 de 2004, nuestro código procesal penal, ha erradicado las pruebas de oficio, entonces facilita y estimula el eficientismo penal al negar la presunción de inocencia y el debido proceso probatorio a los acusados, fruto de un erróneo uso de los espacios jurisdiccio-

7 Artículo 32. Correlación entre Deberes y Derechos. 2. Los derechos de cada persona están limitados por los derechos de los demás, por la seguridad de todos y por las justas exigencias del bien común, en una sociedad democrática. 
nales discrecionales que, según Ferrajoli, todo juez ejerce (1997), en un vano intento de construir un silogismo judicial perfecto que permita justificar una sentencia condenatoria inconstitucional y antigarantista. Por ello, el juicio penal debe erigirse como un saber-poder, lo que se traduce en un verdadero juzgamiento de corte cognoscitivo, donde prime el conocimiento - veritassobre la majestad —auctoritas — del juez. De allí que el tercero súper partes no debe dar cabida a esta institución, y en su lugar, dar aplicación a las garantías procesales que todo acusado tiene: debido proceso probatorio, presunción de inocencia, in dubio pro reo, igualdad de armas. Si prima el poder sobre el saber, entonces se abre la puerta a la injusticia.

Desde la óptica del ordenamiento jurídico constitucional y penal colombiano, y de las garantías universales, la teoría de la carga dinámica de la prueba en materia punitiva es inconstitucional, y por ende, inaplicable. Teniendo como referente lo estipulado en las Reglas de Mallorca y la teoría del garantismo penal de Luigi Ferrajoli, existe una seria contradicción entre lo allí dispuesto y las consecuencias que genera la aplicación de las cargas dinámicas probatorias, ya que las garantías básicas que deben acompañar al procesado durante el la investigación y el juicio se ven seriamente comprometidas: respecto de los derechos del imputado, se desconoce la prohibición de autoincriminación; en cuanto al juicio oral, se transgreden la inmediación y contradicción probatorias, la presunción de inocencia, el principio de in dubio pro reo y la libre valoración probatoria, ya que se puede llegar a una decisión condenatoria sin haberse satisfecho debidamente el estándar probatorio de conocimiento más allá de toda duda razonable.

La carga dinámica de la prueba no tiene cabida alguna en un sistema acusatorio, pues el garantismo "... no tolera alzamiento alguno contra la norma fundamental..." (Alvarado, 2005: 305), de manera que hay que tomar inmediato partido por la Constitución y la ley, para poder alzar la voz exigiendo:

"la libertad;

"la garantía del debido proceso;

"y el goce irrestricto del día de audiencia previa en la Corte de Justicia;

"donde todo ciudadano tiene derecho a ser juzgado imparcialmente por un juez;

"y colocado por él en pie de perfecta igualdad frente a su contradictor; 
"con absoluta bilateralidad de la audiencia;

"y sin la asunción por el juez de actitudes paternalistas con las partes o de tareas que no le incumben conforme con lo normado por la Constitución." (Alvarado, 2005: 307-308).

De esta forma, será posible entonces extraer de Colombia y de Latinoamérica, los rezagos de rancio inquisitivismo imperantes.

\section{BIBLIOGRAFÍA}

Acero, L.G. Bermúdez Muñoz, M. Buitrago, A.M. et al. Memorias del 30 Congreso Colombiano de Derecho Procesal (2009). Bogotá: Universidad Libre de Colombia.

Alvarado Velloso, A. (2005). Garantismo procesal contra actuación judicial de oficio. Valencia: Tirant lo Blanch.

Alvarado Velloso, A. (2006). La prueba judicial (Reflexiones críticas sobre la confirmación procesal). Valencia: Tirant lo Blanch.

Arazi, R. Armienta Calderón, G. \& Berizonce, R. O. (2002). La prueba. Homenaje al Maestro Hernando Devis Echandía. Bogotá: Universidad Libre de Colombia.

Constitución Política de Argentina de 1994.

Convención Americana de Derechos Humanos.

Corte Suprema de Justicia. Sentencia de casación de nueve de abril de 2008, radicado 23754 .

Corte Suprema de Justicia. Sentencia de casación de veintisiete de marzo de 2009, radicado 31103.

Corte Suprema de Justicia. Sentencia de casación de trece de mayo de 2009, radicado 31147.

FerRajoli, L. (1997). Derecho y razón. Teoría del garantismo penal. Segunda edición. Madrid: Trotta.

Organización de LAS NaCiones Unidas (1992). Proyecto de reglas mínimas de las Naciones Unidas para la administración de la Justicia Penal. [en línea] Disponible en: http://www.cidh.org/PRIVADAS/reglasdemallorca. htm. [Visitado el 23 de junio de 2010]

Peyrano, J. W. (director) \& Lépori White, I. (coordinadora). (2004). Cargas probatorias dinámicas. Santa Fe: Rubinzal Culzoni Editores.

Roxin, C. (2000). Derecho procesal penal. Buenos Aires: Ediciones del Puerto. 